\title{
Evolución y evaluación económica de 1990
}

Fco. Javier Ibisate

Feliz Año Nuevo nos dijimos el día primero de enero, los unos por rutina, los otros con la esperanza de que la paz y la recuperación económica florecieran con las primeras lluvias de mayo. Habia además otra razón para dejarse llevar del optimismo: allá en Europa estaban diciendo que el siglo-XXI comenzaba en 1990. Se adelantaba de una década el segundo milenario, en que la carrera armamentística se transformaba en diálogo para la paz, para la desarmamentización de las grandes potencias y superpotencias. Los sorpresivos cambios en la Europa del Este, sorpresivos por su celeridad y su drasticidad política, ampliaban el horizonte de un gran mercado común de 800 millones de habitantes y de una vasta plataforma para la recuperación económica mundial. Desde el lejano Este (Japón) y desde el occidental Oeste (USA) llegaban los embajadores del crédito y de la inversión. Una nueva era parecia relegar al olvido las dos décadas de estanflación mundial.

Tan importante como el horizonte económico era el nuevo perfil político: las bruscas convulsiones sociales eran un reclamo contra la intolerancia política, una cortapisa a las oligarquias posesionadas del todo poder y del todo saber, un rechazo de la corrupción administrativa y del dogmatismo cultural. Por su parte, la macroencuesta europea sondeaba las expectativas de ocho paises del Este y Oeste colocando como primera premisa del nuevo orden internacional a la democracia. A la nueva era se le llamó "post-perestroika"; porque perestroika significa secuencialmente reforma-reestructuración-revolución. La nueva-era significa una fase de transición donde los unos y los otros debian realizar serias revoluciones de cara a un neo-socialismo o a un neo-liberalismo. No quedaba muy clara la disyuntiva, porque neo-socialismo significa 
para unos "no-socialismo", y neo-liberalismo significa para otros "noliberalismo". Más que el triunfo de un sistema sobre otro sistema el prefijo de "neo" quiere decir que el siglo-XXI debe iniciarse con algo nuevo, algo distinto del socialismo-real y del capitalismo-real, que han marcado conflictivamente la historia de la última centuria desde la Rerum Novarum de los 1890 hasta la Post-Perestroika de los 1990.

$Y$ es que hablar del siglo-XX es hablar de nuestro ano-1990, o mejor aún de nuestra pasada década 1980-1990. El siglo-XX ha sido el gestador de los enfrentamientos y de los imperialismos ideológicos, políticos, económicos y militaristas. Lo que más floreció fue la carrera armamentistica, las dos grandes guerras y las múltiples guerrillas; y en el mercado internacional se amplian las rutas del comercio de armas y también de la droga: dos formas de enriquecimiento y destrucción de la persona humana. En el siglo-XX se habló y se escribió mucho sobre el desarrollo económico y social; se descubrieron tres mundos dentro del mundo, pero sus intereses eran contradictorios. Los intereses del primer mundo no eran los del segundo mundo; sobre todo que la suerte del tercer mundo no corria pareja del crecimiento en el primero y segundo mundo. En ese mapa-mundi se aprecia cada vez con mayor claridad la presencia de una ley de la gravedad económica: todo el hemisferio-Norte presionaba fuertemente sobre el Sur hasta la extracción de una impagable deuda externa.

Si en el Norte creció la guerra y la carrera armamentística, en el Sur estalló la guerrilla y el tráfico de armas. No presentaban colores alegres los circuitos monetarios de la deuda extema, del comercio de armas, ni el lavado de la droga. Los residentes del Norte se han preocupado más por frenar el flujo de la droga, que el flujo de la deuda y de las armas. Deuda y armas hacen cada vez más difícil el diálogo Norte-Sur y EsteOeste dentro de nuestro estrecho istmo. Seguimos en el siglo- $X X$, un siglo bastante triste. Con razón dicen en Europa que en 1990 debe comenzar el siglo-XXI, donde neo-socialismo y neo-liberalismo significan "no" al socialismo y al capitalismo de la pasada centuria, y un "si" a "la democracia económica humana" (Ota Sik). "Todo el mundo necesita reestructuración" nos dice M. Gorbachov.

\section{1990: segulmos en el siglo-XX}

Era necesaria esta introducción para caer en la cuenta de que nosotros vivimos aún en el siglo- $X X$, bastante distanciados de los nuevos ideales del siglo-XXI. Al fin y al cabo 1990 es un apéndice de la década iniciada en 1980, porque los grandes reguladores de nuestra economla y de nuestra coexistencia social siguen siendo la guerra, la ad- 
versa coyuntura internacional y la ayuda externa para sostener la guerra y aliviar la crisis económica. En este mismo tono se expresaban los informes oficiales a comienzos del ano tratando de explicar por qué se retrasaba de algunos meses el calendario de la recuperación económica. Tres eran las causales de la trabazón económica: la ofensiva de noviembre-diciembre, 1989; la sensible caida de los precios del café luego de la ruptura del convenio internacional, y la reducción de la ayuda externa. Ahi están presentes los tres grandes reguladores de la economía nacional, que actuaron más negativamente todo a lo largo de la década de los 1980. Para la lucha electoral (1989) habia que poner en el escenario a otros autores: el Estado omnipresente, las reformas estructurales y las ideologías subversivas importadoras de la guerra. Ya hemos comentado en anterior publicación ${ }^{1}$ que tal interpretación oficial no es muy objetiva ni muy histórica.

Lo histórico y más objetivo es que a lo largo de 1990 siguen presentes, alternando efectos negativos y positivos, la guerra, la coyuntura internacional y la ayuda externa económica y militar. Lo que ha sucedido económica, política y socialmente se deriva, en primera instancia, de estos tres reguladores, que determinan los posibles éxitos o recesos de las neopolíticas de estabilización y ajuste estructural. Es lógico que los informes y los informadores oficiales se ciñan a resaltar los efectos más favorables de la superficie macroeconómica: el índice del volumen de actividad económica, la mayor disponibilidad de reservas intemacionales netas, el incremento de los depósitos bancarios, la reducción del déficit fiscal y de la tasa de inflación, el auge sensible de las exportaciones y el flujo sostenido de las remesas familiares $(\$ 10$ millones por semana), amén de otras cualidades adjudicadas al modelo y que debemos comentar. Al hacer la evaluación económica de 1990 no debemos alucinarnos por estos resultados anuales macroeconómicos que fácilmente pueden cambiar de ritmo y de dirección, no sólo en virtud de aquellos tres grandes reguladores, sino también y sobre todo porque nos resistimos a entrar con los pies en la vía democrática del siglo-XXI.

La Administración Pública tiene que dividirse en poderes y departamentos ministeriales, defensa-seguridad, justicia.... Asamblea y Corte Suprema. Pero la realidad social integra en la misma unidad estas diversas partes y el cuerpo total no puede estar sano si varios de sus miembros están enfermos o mutilados. Lo superticialmente económico no augura la estabilización de cuerpo social si los puntos de agenda debatidns en el diálogo nacional muestran más bien nuestra debilidad

1. Ibisate Foo. Javier: "El programa de ajuste estructural: una herencia dificil". Realidad Económico-Social. NN 15. Mayo-junio, 1990. 
democrática. El déficit fiscal no es simplemente un desequilibrio de contabilidad nacional; es más bien el resultado de otras deficiencias gubernamentales bastante afines al modelo neoliberal. Serias deficiencias al seguir buscando la solución en la guerra, retrasando y dificultando el diálogo y la negociación. Serias deficiencias en la administración de la justicia y del control efectivo de la impunidad. Serias deficiencias en todo el proceso de desmilitarización en búsqueda de una sociedad civilista. Serias deficiencias en la interpretación y realización de los derechos humanos. Deficiencias sensibles en la interpretación de las causales y de los actores principales del retoceso social, tal como ha quedado patente en la última reunión de Presidentes del istmo tenida en Costa Rica, que condena unilateralmente a una de las partes, que apoya más que la implicitamente el regreso al militarismo y a la guerra prolongada y que relega al olvido los puntos de agenda aprobados en anteriores sesiones del diálogo. Con ello regresamos al enfrentamiento ideológico, a la desconcertación social, al régimen de la impunidad militar, a la militarización triunfalista, a la inseguridad generalizada, a la desconfianza de los procesos electorales, a la pérdida de la democracia y al propio descrédito de los posibles logros macroeconómicos del modelo. Para la población general, para esa parte de la sociedad que llamamos pueblo, todo el cunjunto forma parte del mismo modelo neoliberal que centra su atención en algunos resultados cuantitativos, pero que carece de visión o de fuerza para enmendar todo este desquiciamiento humano.

\section{Los exltos macroeconómlcos de 1990}

No está de más hacer preceder la interpretación de los resultados macroeconómicos, oficiales y no oficiales, con unas premisas introductorias. Desde hace tiempo ha sido provertial el espiritu de iniciativa, el dinamismo y la ingeniosidad de la población laboral salvadorena. Es una cualidad congénita admirada por visitantes extranjeros que contrastan esta simbiosis de hacer economia en medio de la guerra; con economia de guerra queda un espacio para la economía civil formal e informal. Esta estructura motriz es el eje de todo proceso económico, acciona y reacciona a las presiones internas y externas incluso en los momentos de mayor crisis. Esta consideración nos evita el equlvoco de atribuir todo éxito a todo fracaso a un simple cambio de modelo; al fin y al cabo los modelos económicos son modelados por las estructuras de fondo, sean ellas motrices o de freno.

A partir del credo "cambiar para mejorar" se puede afirmar alegremente que los resultados macroeconómicos globales son el prefacio de una recuperación social. Posible espejismo de confundir resultados 
cuantitativos con avances sociales. Este optimismo oficial si tiene un aspecto positivo: se publican profusamente las politicas y los logros; se calendarizan las medidas y los tiempos predestinados a la estabilización, al juego del ajuste estructural y a la recuperación venidera. EI modelo macroeconómico aparece como un entreverado de variables externas e internas, reales y monetarias, de corto y mediano plazo, que ayudan a entender mejor la compleja coexistencia de problemas estructurales, de soluciones alternativas asi como las probables consecuencias económicas y sociales. Este es un avance positivo, una expresión más técnica de la interdependencia macroeconómica, tomando en cuenta el silencio informativo y el top-secret de pasadas instituciones públicas y monetarias. Un avance significativo es el aporte de varias instituciones de análisis e investigación económica y sobre todo que estos cuestionamientos sean reflexionados y cuestionados por las asociaciones y gremiales del sector laboral.

En la interpretación de los agregados macroeconómicos subyace un error de composición sui-generis: confundir el todo con las partes, es decir que todos los grupos o partes componentes mejoran cuando se da un incremento en el agregado global. Uno de los temores más fundados es que las politicas de ajuste estructural son, al menos inicialmente, discriminantes en sus efectos sociales. Este temor queda explicitado en el mismo Plan de Desarrollo al dedicar su segunda parte. Desarrollo Social, a un conjunto de políticas de compensación social, administrados esencialmente por el Estado, y al crearse el Fondo de Inversión Social (FISS) como alternativa para aliviar la pobreza. Se presume que el modelo genera efectos discriminantes y esta es la presunción de las gremiales laborales. Estas consideraciones explican que el actual modelo económico genere a la vez expectativas positivas y negativas, sin olvidar que él viene configurado por aquellos grandes reguladores, la guerra, la coyuntura internacional y las alternativas de la ayuda externa. Aunque a final de año se haga un inventario de objetivos y resultados, no podemos dividir el proceso en secciones anuales de borrón y cuenta nueva. El análisis de las variables y logros macroeconómicos hay que extenderlo a lo largo del tiempo y hacia bo profundo de los efectos estructurales sobre los grupos y partes componentes del conjunto, si queremos fundar mejor las expectativas del próximo futuro. A todo ello ayudarla una positiva concertación de análisis y de propuestas correctivas.

1) Un primer logro macroeconómico, oficialmente publicitado, es el incremento del indice de volumen de actividad económica (IVAEF. EI informe del GAES-MIPLAN reporta la evolución del IVAE para el periodo enero-septiembre 1990, quedando en expectativa los resultados de 
los tres últimos meses bastante turbulentos por la llamada ofensia insurgente y el posible efecto retardado de los precios del petróleo. Este indicador, IVAE 1984=100, marca un mayor activismo económico de 5,45 en 1990 comparado con el indice 4,20 en 1989 (cuadro 1). Sin embargo, no todos los subsectores muestran tasas de evolución similarmente positivas. El sector agropecuario acusa un sensible aumento de ritmo, pasando de $-2,00$ en 1989 a 3,21 en 1990. Sin duda este es un sector que, en conjunto, se ha sentido catalizado y beneficiado por el nuevo tipo de cambio aplicado a las exportaciones tradicionales y no tradicionales, que indujo al incremento de superficies sembradas. La excepción es el caso del algodón, más golpeado localmente por el conflicto armado, amén de los elevados costos de sus insumos, y que no logra satisfacer la demanda interna de materia prima. Las buenas cosechas de granos básicos son obra de la naturaleza, y no tanto obra del príncipe como parecen atribuirse los gestores del modelo.

Hay dos sectores que, siendo claves para la recuperación económica y la generación de empleo, han resentido un menor ritmo de crecimiento e incluso una contracción: el sector industria y el sector construcción (Cuadro 1). El sector industria sigue encontrando serias dificultades, entre otras dificultades financieras, para realizar la recon-

\section{Cuadro 1}

Indice de Volumen de la Actlvidad Económica (IVAE)

(Base $1984=100$ )

\begin{tabular}{lrrrrrrrrr}
\hline & \multicolumn{2}{c}{$\begin{array}{c}\text { Enero-Junlo } \\
\text { SECTOR }\end{array}$} & \multicolumn{2}{c}{ Enero-Jullo } & \multicolumn{2}{c}{ Enero-Agos. } & \multicolumn{2}{c}{ Enero-Sept } \\
& 1989 & $\mathbf{1 9 9 0}$ & $\mathbf{1 9 8 9}$ & $\mathbf{1 9 9 0}$ & $\mathbf{1 9 8 9}$ & $\mathbf{1 9 9 0}$ & $\mathbf{1 9 8 9}$ & $\mathbf{1 9 8 0}$ \\
\hline Indice General & 3.48 & 6.03 & 3.97 & 5.24 & 4.14 & 5.70 & 4.20 & 5.45 \\
Agropecuario & 1.68 & 8.13 & -0.06 & 2.11 & -1.50 & 2.97 & -2.00 & 3.21 \\
Industria & 6.64 & 1.88 & 7.65 & 2.97 & 7.82 & 4.18 & 8.43 & 3.52 \\
Comercio & 1.51 & 8.64 & 4.44 & 8.39 & 5.84 & 8.24 & 6.17 & 8.02 \\
Construcción & 8.98 & -3.93 & 8.81 & -3.10 & 10.44 & -4.19 & 9.00 & -3.50 \\
Electricidad & -0.07 & 8.33 & 1.71 & 7.66 & 2.31 & 7.10 & 2.61 & 6.73 \\
Transporte & 10.46 & 7.48 & 9.41 & 7.17 & 8.37 & 9.50 & 8.50 & 8.60 \\
Admón. Pública & -6.68 & 7.71 & -6.68 & 7.71 & -6.68 & 7.71 & -6.68 & 7.71 \\
\hline
\end{tabular}

Fuente: Banco Central de Reserva de El Salvador.

2. Fuentes bibliográficas: GAES-MIPLAN: "Evolución económica y social" Tercer informe trimestral, 1990. FUSADES: Boletines de "Informe económico semanal". 
versión industrial y mejorar su capacidad competitiva interna y externa. De acuerdo a las encuestas", entre las principales razones que los empresarios aducen para no hacer mayores inversiones se encuentran: inestabilidad de la moneda (31\%); altos intereses de los créditos $(22 \%)$ y baja rentabilidad de las inversiones (21\%) "(GAES-MIPLAN, p. 95). Las encuestas de FUSADES muestran que dentro del sector industrial son la pequena y microempresa quienes encuentran mayores obstáculos para mejorar su productividad; ; y este amplio subsector es un posible generador de amplio empleo.

La declinación del sector construcción tiene causas y efectos que se resentirán en el mediano plazo. La contracción está asociada al incremento del $20 \%$ en la mano de obra, al alza de precios de los materiales importados y al encarecimiento de los intereses activos. Si el costo de las divisas externas y del crédito interno desacelera y encarece la construcción ello tendrá un doble efecto: por una parte ya se ha dejado sentir en el elevado índice de inflación de la vivienda $(24.9 \%$. Por otra parte, siendo la construcción-vivienda subsectores claves de la economia como demandantes de insumos y como oferentes de bienes intermedios, su contracción generará logicamente un efecto multiplicador-acelerador a la baja. EI FISS y los programas de compensación social deberán estar listos para echar el flotador.

Habiéndose elevado el IVAE general también se han elevado los indices de actividad del transporte y electricidad, por ser ellos servicios básicos del conjunto económico; por la misma razón vamos a ver a estos dos sectores como grandes demandantes de importaciones requeridas para sostener sus servicios. Queda como interrogante los efectos retardados de una prolongada alza de los precios del petróleo sumado a la destrucción de las fuentes y vías de transmisión de energía eléctrica. $Y$ queda otro interrogante secundario y siempre en litigio: el análisis técnico del GAES (pp. 133-142) sobre el impacto de los precios del petróleo en la economía salvadorena deja entender, en sus reflexiones finales, cierta falta de transparencia en la determinación de precios internos y cierta sobredosis de impuestos y sobrecargos... (p. 142). Se aprecia claramente que en el subsuelo del IVAE actúan la guerra y la coyuntura internacional.

2) Uno de los objetivos primordiales del ajuste estructural es la recomposición del equiibrio externo de los componentes de la balanza de pagos. Los nueve primeros meses del ano han mostrado un re-

3. FUSADES: "Clima de negocios y actividad económica". 3er. trimestre, 1990. p. 6. 
sultado global favorable, traducido en un superavit de $\$ 196$ millones. Este saldo positivo resulta de una reducción sustancial del deficit en cuenta corriente y de unos ingresos netos de $\$ 251,7$ millones en la cuenta de capital (cuadro 2); ello es resultado de la reprogramación de parte de la deuda extema (otra parte fue pagada en efectivo) y del flujo

\section{Cuadro 2}

Balanza de pagos

(millones de US\$

\begin{tabular}{|l|r|r|r|}
\hline & \multicolumn{2}{|c|}{ Enero-Septlembre } & Varlación \\
\cline { 2 - 3 } & 1989 & 1990 & Absoluta' \\
\hline Cuenta Corriente & -129.4 & -55.7 & 73.7 \\
Balanza Comercial & -430.3 & -409.1 & 21.2 \\
Servicios Netos & -31.1 & -18.4 & 12.7 \\
Transferencias Netas & 332.0 & 371.8 & 39.8 \\
Cuenta de Capital & 31.0 & 251.7 & 220.7 \\
Capital oficial & 85.8 & 79.1 & -6.7 \\
Capital Bancario & 5.0 & 71.1 & 66.1 \\
Capital Privador & -59.8 & 101.5 & 161.3 \\
& & & \\
Saldo Balanza de Pagos & -98.4 & 196.0 & 294.4 \\
& & & \\
Reservas Internacionales Netas & 38.1 & -107.2 & -145.3 \\
Pagos Diferidos & 60.3 & -91.6 & -151.9 \\
Atrasos Deuda Corriente 1990 & Na & 2.8 & 2.8 \\
Nivel de R.I.N. & & & \\
Saldo Pagos Diferidos 1989 & 900.0 & 401.1 & 201.1 \\
\hline
\end{tabular}

Fuente: Banco Central de Reserva de El Salvador y GAESMIPLAN.

$1 /$ Con respecto al mismo período del año anterior.

2/ Incluye errores y omisiones.

positivo de divisas a la cuenta de capital privado. (GAES; p. 79). Con ello El Salvador pasa a ser sujeto de crédito del FMI. No sólo el resultado global es favorable sino que también lo son las expectativas oficiales. ¿En qué se fundamenta este optimismo?

Como primer dato relativamente positivo está la reducción del deficit de la balanza comercial. La política cambiaria ha beneficiado la exportación de café, pese a la sensible caida de los precios-1989 y pequeno 
remonte de los mismos a partir del mes de mayo. Queda ahora en duda el resultado final de la actual cosecha luego de los vientos y lluvias tardias que pueden dar al traste con las anteriores proyecciones; al interrogante metereológico se suma el temor de las elevadas reservas de café en el mercado europeo y el impacto que sobre esta demanda pueda originar el drama del golfo-pérsico. Siendo para nosotros el café una variable determinante, es al mismo tiempo una variable determinada por la coyuntura internacional y los imprevistos naturales. También en la caña de azúcar se habian ampliado las superficies y se habian diversificado las especies sembradas, pero el precio intemacional decayó desde junio debido, al parecer, a las grandes reservas de cana y remolacha azucarera. Por su parte el algodón no logra despegar, porque aparte de su conflictiva localización geográfica se le han encarecido sensiblemente los precios de sus insumos. Ni todos los éxitos ni todos los desperfectos se pueden adjudicar al modelo de turno.

En los informes oficiales se destaca fervientemente el notorio incremento de las exportaciones no-tradicionales. Aqui es importante el calificativo de no-tradicionales. Sin minusvaluar los esfuerzos, un in-

\section{Cuadro 3 \\ Resumen de la Composiclón de Exportaciones (Milones de US\$)}

\begin{tabular}{|c|c|c|c|c|c|c|c|}
\hline & & & & \multicolumn{4}{|c|}{ Enero-Septlembre } \\
\hline & \multicolumn{3}{|c|}{ Enero-Septiembre } & \multicolumn{2}{|c|}{$\begin{array}{l}\text { Varlaclón } \\
\text { Absoluta' }\end{array}$} & \multicolumn{2}{|c|}{$\begin{array}{l}\text { Varlación } \\
\text { Porcontual' }\end{array}$} \\
\hline & 1988 & 1989 & 1990 & 1989 & 1990 & 1989 & 1990 \\
\hline Tradicionales & 329,23 & 235.87 & 274.8 & -93.4 & 38.9 & $=28,4$ & 16.5 \\
\hline Cal $^{2}$ & 299.8 & 216.4 & $\overline{245.4}$ & -83.4 & 29.0 & -27.8 & 13.4 \\
\hline Algodón & 0.53 & 1.0 & 1.4 & 0.6 & 0.4 & 88.7 & 40.0 \\
\hline Azúcar & 19.2 & 10.3 & 19.6 & -8.9 & 9.3 & -46.5 & 90.7 \\
\hline Camarón & 9.7 & 8.2 & 8.4 & -1.5 & 0.2 & -15.6 & 2.6 \\
\hline No tradicionales & 152,9 & 1718 & 208.9 & 18,9 & 371 & 124 & 21.6 \\
\hline MCC & 102.4 & 119.7 & 124.9 & 17.3 & 5.2 & 16.9 & 4.3 \\
\hline Resto del Mundo & 50.47 & 52.1 & 84.0 & 1.6 & 31.9 & 3.2 & 61.2 \\
\hline Total & 482.1 & 407.7 & 483.7 & -74.4 & 76.0 & -15.4 & 18.6 \\
\hline
\end{tabular}

Fuente: Banco Central de Reserva de El Salvador y GAES/,MIPLAN

$1 /$ Con respecto al mismo período del año anterior

2/ Incluye exportaciones de caf́́ soluble. 
cremento inicial es algo notorio alli donde no existia tradición sea de producción, sea de exportación. A la iniciativa nacional se agrega la simplificación de trámites y permisos de exportación. Al ser exportaciones no tradicionales se ha cuestionado el quienes son los beneficiarios de su proceso de producción y de comercialización. Algunas gremiales obrero-campesinas, la UNOC en concreto, han develado el hecho de que los pequenos productores en poco o en nada se han beneficiado de las favorables políticas cambiarias, mientras que los mercaderes intermediarios se quedan con la parte del león. La queja llegó hasta el Congreso Norteamericano asl como la acusación de antipatriotas. Cuando el rio suena agua lleva, porque semejante queja se escucha en los pequenos productores de granos básicos y en las asociaciones campesinas para quienes un $15-17 \%$ del alza salarial ni compensa la tasa de la inflación, ni los hace coparticipes de los extrabeneficios de las medidas cambiarias. Todos ellos se sienten miembros del gremio de la ventaja comparativa o mano de obra barata.

Si las exportaciones muestran resultados contables positivos junto con efectos sociales cuestionados, las importaciones traducen a la vez los esfuerzos y las dificultades de la recuperación económica. Como lo muestra el cuadro 4, el monto global de las importaciones sigue un increscendo sostenido: $\$ 754,2$ millones (1988); $\$ 838,0$ millones (1989) y $\$ 892.8$ millones (1990) en los nueve primeros meses. Ello ha generado un sensible, aunque menor déficit, de $\$ 409$ millones. Hay variantes importantes en la estructura de las importaciones donde afectan las medidas cambiarias, la inflación externa y nuestra rigida dependencia. En las importaciones de bienes de consumo predominan los rubros de luz, combustible, transporte y comunicaciones en calidad de bienes y servicios básicos del proceso económico. Igualmente se ha elevado el gasto en bienes intermedios, con mención especial del petróleo, donde el alza de los precios entorpece al avance de la recuperación. Pero se enciende una luz-roja con vistas al mediano plazo: se han contraido sensiblemente las importaciones de capital, lo cual cuestiona el proceso de inversión y de capacidad competitiva. (Cuadro 4) El informe del GAES es expedito al sehalar las razones: "1) el lento proceso de reconversión industrial y el moderado crecimiento del sector industria en 1990; 2) la contracción experimentada en el sector construcción; 3) la reducción de la demanda por este tipo de bienes debido al incremento del tipo de cambio; y 4) en alguna medida, el incremento de los precios externos en los mercados internacionales" (p. 81).

La misma política cambiaria que favorece unilateralmente el proceso exportador, aunque siempre sometido a los vaivenes del mercado externo, comienza a dificultar las importaciones de bienes de capital 
necesarios para mejorar la productividad y competencia en el mercado interno y externo, aparte de generar un componente de inflación importada. La coyuntura internacional nos sacude a babor y estribor de la balanza comercial embarcados como estamos en un régimen de economia abierta al mercado externo. Siendo éste un problema estructural de nuestra economia trunca y dependiente es uno de los puntos cuestionables del ajuste estructural, donde las políticas cambiarias pueden alentar a algunos sectores económicos en la misma medida en que pueden trabar la recuperación de otros sectores, sobre todo si se tome en cuenta que ni nuestra situación política ni el actual estancamiento de la economía mundial propician la llegada de inversión y tecnologia extranjera. La necesidad de fomentar las exportaciones debe ir acompanada con la necesidad de selección de las importaciones netamente necesarias para la inversión.

Si la inversión no llega, siguen llegando capitales de fuera, sea en forma espontánea como las remesas familiares, sea como consecuencia de la reprogramación de la deuda con el Club de París. Se suman aqui los financiamientos, y refinanciamientos de deudas oficiales y del BCR a las cuantiosas remesas de emigrantes más algunos primeros indicios de repatriación de capital. Otras "fuentes no especificadas" explicarian el ingreso neto de capital privado (Cuadro 2). Han supuesto un gran alivio en el presente ejercicio la renegociación de parte de la deuda externa en condiciones relativamente favorables de plazos, años de gracia e intereses, siendo bastante llamativo que nuestros acreedores hayan sobrepasado en unos $\$ 5$ millones la propuesta de negociación gubernamental; lo habitual es que el pais solicitante pida un poco más para obtener un poco menos. De cualquier manera, esta reprogramación de la deuda externa, sumada a un notable aumento de donaciones esperadas, ha generado un saldo favorable en la balanza de pagos y una mayor disponibilidad de reservas internacionales netas suficientes para cubrir unos tres meses de importaciones. A estos esfuerzos oficiales hay que anadir que nuestra balanza de pagos se ajusta y se sostiene gracias a los "pobre-dólares" de los emigrantes, que de acuerdo a cifras publicadas rondan y sobrepasan los $\$ 530$ millones al ano ( $\$ 10$ millones/semana). Es interesante que los pobres colaboran a salvar el modelo y la pregunta es si el modelo colaborará a salvar a los pobres.

3) Un área de primordial importancia para el buen juego de las políticas de estabilización y de ajuste estructural es el presupuesto estatal o finanzas públicas; se adicionan los i jumnentos '‘ćricos y los objetivos del equilibrio económico. Por un ladc. En un mooelu neoliberal se reduce el papel del Estado a una función subsidiaria. Pareceria que 


\section{Cuadro 4 \\ Resumen de la Clasificación de las Importaciones \\ (Millones de US\$)}

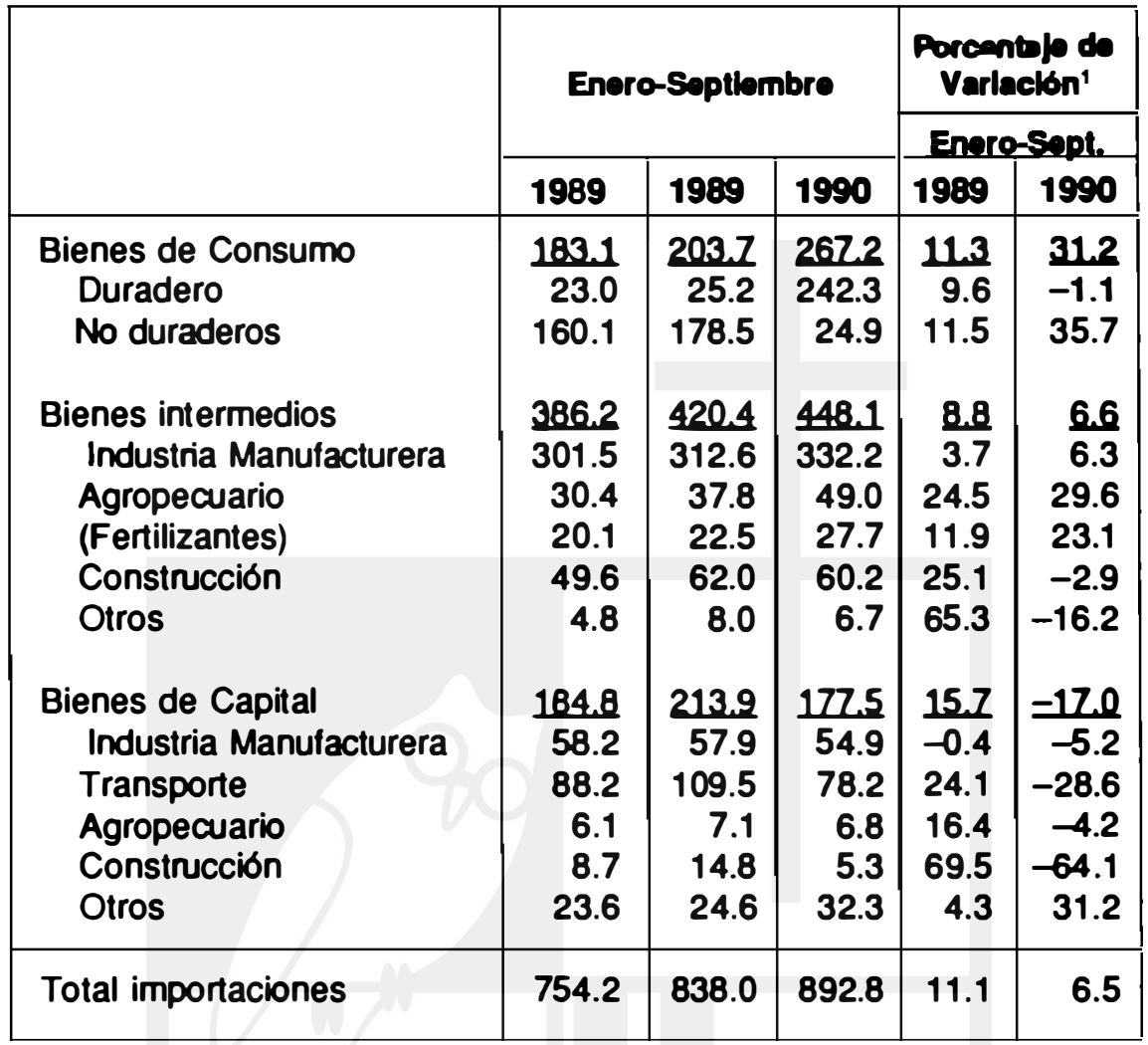

Fuente: Banco Central de Reserva de El Salvador y GAESMIPLAN.

$1 /$ Con respecto al mismo período del año anterior.

en la conducción y reconversión económicas no hay espacio para los dos desde el momento que una mayor participación estatal agota la iniciativa y la creatividad privada. Es más bien un enfoque de superficies de poder o lucha por el poder que de integración de funciones. La teoría se ve avalada con el tergiversado argumento del fracaso de las economias del Este-europeo, llamados socialismos-reales para significar que han sido socialismos-irreales, es decir, no socialismo. De todas formas un mal argumento se utiliza para cambiar una realidad antisocial. Desde la perspectiva del equilibrio macroeconómico se parte, como dato estadístico, de los crónicos déficits fiscales, generadores importantes de inflación alentada por un crédito inorgánico y transmisor 
de su propio desajuste a la balanza (general) de pagos. Si a ello se anade la factibilidad de corrupción en el uso de la propiedad púbica y la inercia administrativa, no le queda al Estado otra función que la de súbdito complementario del sector privado.

Desde la otra vertiente de la convivencia civil, si el militarismo absorbente domina el territorio de la administración de justicia y de la interpretación y adjudicación de los derechos humanos, las funciones del Estado quedan bien diluidas en un pais donde la impunidad y la discriminación social desfiguran la imagen intema y extema nacional. Nuestro Plan de Desarrollo toca muy tengencialmente el tema de los derechos humanos sociales, mientras que los principios filosóficos y los planteamientos económicos introductorios pivotean sobre una visión individualista y egocentrista. Al desmembrar y aislar las funciones estatales, el tratamiento del presupuesto estatal adquiere un cariz excesivamente economicista y global, reducido a comparaciones contables.

Desde este enfoque global los nueve primeros meses del ejercicio fiscal-1990 han logrado disminuir el déficit fiscal por reducción del gasto, del desahorro corriente y por un incremento del $50,9 \%$ de las donaciones (cuadro 5). La estructura del presupuesto-1990 repite y precede la estructura de 1989-1991, y una vez más el gasto de guerra, bajo título de defensa-seguridad, permanece intacto en un programa social de "cambiar para mejorar". Aparte de que la guerra siempre ha sido deficitaria, pareceria que al no cambiar la estructura del presupuesto tampoco se quiere cambiar la estructura del diálogo-negociación.

El hecho de que se mantengan serias discrepancias acerca de las teorias y funciones estatales en economias subdesarrolladas no desmerita el esfuerzo que esta rama del ejecutivo, sin duda con buena voluntad, viene realizando para disminuir el desahorro y la misma cornpción; aunque da la impresión que se persigue más la cornupción vestida de verde, que otras corrupciones más antiguas y más irritantes socialmente. De todas formas ya es un avance que se introduzca en nuestro diccionario civil el concepto de corrupción, aunque todavia queda largo trecho para deslindarla del compadrazgo, la mordida, el derecho, la fuerza y otros canales por donde se ramifican la cornupción.

El resultado gobal, bajo forma de reducción del déficit fiscal, obedece a tres razones: la mayor recaudación tributaria unida a una política de austeridad y racionalización del gasto corriente; un mayor ingreso de donaciones, y una menor ejecución del programa de inversiones del Gobierno Central, compensado parcialmente por la descentralización del presupuesto extraordinario. Análisis más concretos tratan de 
Cuadro 5

Operaclones FInancleras del Goblerno Central Consolldado (Millones de colones)

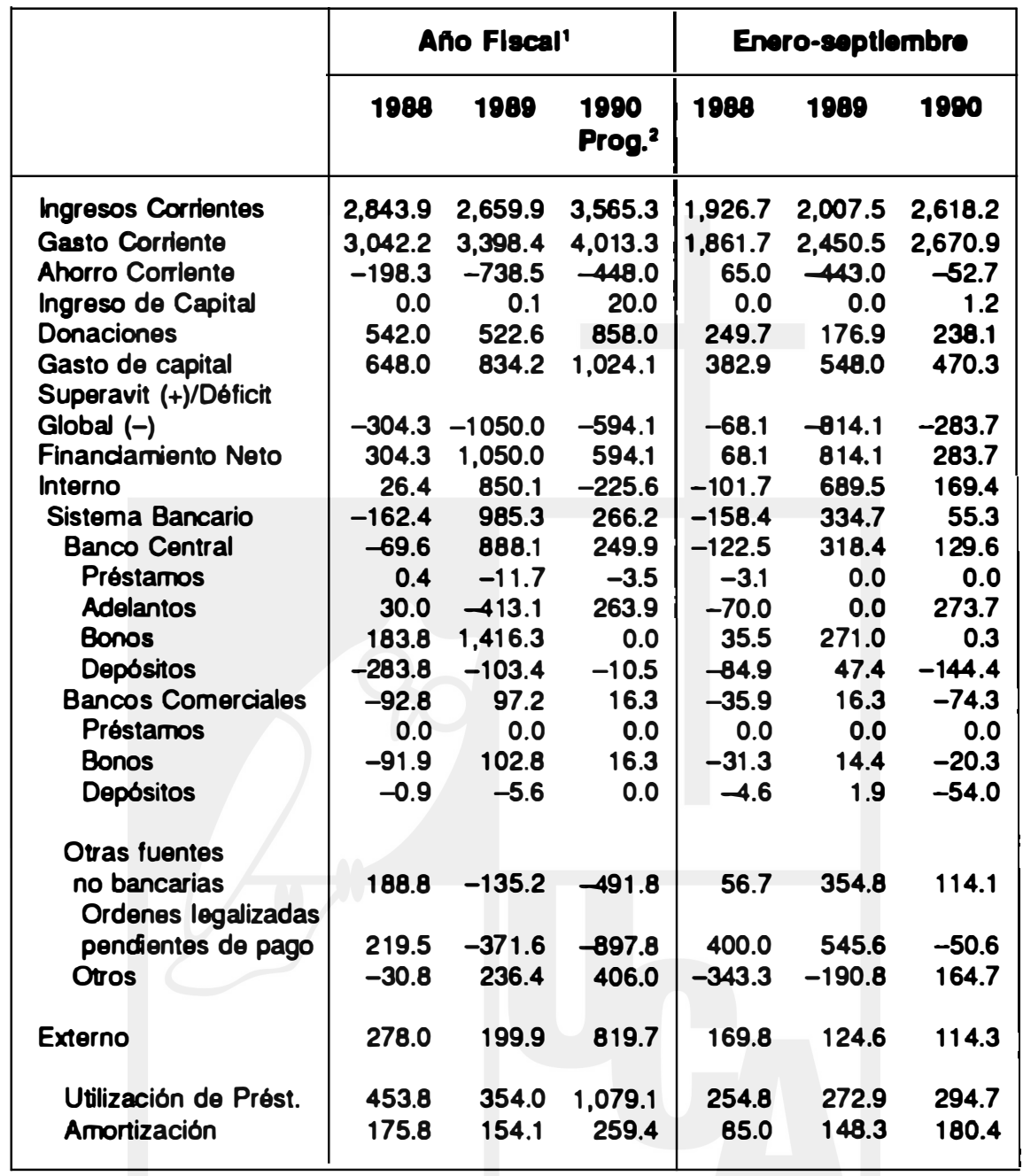

Fuente: Ministerio de Hacienda y Banco Central de Reserva de El Salvador.

$1 /$ Enero a diciembre.

2/ Estos datos ditieren de los que aparecen en el informe semestral, debido a que incluyen los ajustes del programa con el FMI. 
pormenorizar el efecto social de la composición de los impuestos directos e indirectos, porque el común de la población resiente especialmente el gravamen de estos últimos mientras que no se logra controlar la evasión fiscal de múltiples contribuyentes. Se han realizado esfuerzos técnicos para simplificar el sistema impositivo, introducir techos superiores de rentas imponibles, reducir execenciones fiscales y en la medida posible alentar fiscalmente la reinversión financiera del sector privado. Todavía nuestro vacilante sector productivo no acaba de situarse entre los apremios de las políticas fiscales, arancelarias y crediticias, reclamando una graduación en el modo y en el tiempo de su aplicación.

De cara al mediano plazo y al problema de la compensación social se plantea un serio interrogante por la reducción del $14,2 \%$ del gasto de capital (Cuadro 5), debido básicamente a la reducción de la inversión real del Gobiemo Central. Si tomamos en cuenta que el Plan de Desarrollo Social confía al subimperio del Estado áreas tan importantes como la educación, la salud-nutrición, la vivienda, la familia, la previsión social-empleo y el deterioro ecologico, este crecimiento de necesidades básicas familiares y nacionales corre el peligro de verse desatendido y con ello peligra el éxito social del modelo. Al parecer se combinan aquí razones teóricas y prácticas: reprogramación de inversiones, controles que aseguren su transparencia, menor capacidad de ejecución del Gobierno Central bajo la modalidad administrativa y la paralización o mayor lentitud de algunos proyectos por problemas de desembolsos de recursos externos y de procedimientos internos de AID. (GAES; p. 62) Se espera compensar este rezago por transferencias de programas de inversión a las alcaldias e instituciones descentralizadas con recursos del presupuesto extraordinario. Junto con los aspectos positivos de un proceso de descentralización, recientes investigaciones indican que en los proyectos del presupuesto extraordinario también se presentan problemas de control, de auditorías internas, lentitud de trámites, condicionamientos políticos y, siendo hombres de la misma lengua y raza, la corrupción puede agregarse a la lista. La práctica del doble presupuesto, ordinario y extraordinario, aparte de que pueden ser 0 no ser complementarios en sus objetivos económicos y políticos, plantea un cuestionamiento: los proyectos de inversión del presupuesto extraordinario ¿supondrán un incremento en el gasto de funcionamiento del presupuesto ordinario ${ }^{4}$

4. Flores Jurado Rubia R., et alii: "Génesis y contribución de la Asistencia Norteamericana a través del Presupuesto Extraordinario de reactivación económica en la coyuntura salvadoreña de 1983-1988". Tesis de grado. UCA; septiembre, 1990. 
Algo queda claro a modo de interrogante: dada la destrucción física y la obsolescencia técnica de la infraestructura y del equipo productivo. la contracción de importaciones de bienes de capital privado y la actual reducción de la inversión real del Estado no aseguran las bases físicas requeridas para una cercana recuperación económica, ni son agentes multiplicadores del empleo requerido para asegurar una mayor demanda disponible. Los resultados globales de la superticie macroeconómica pueden ocultar serias fallas tecnológicas en las bases del sistema y por ello las proyecciones optimistas de fin e inicio de ano deberian ser más cautelosas. La cercania de las elecciones de marzo no deberian alentar proyecciones demasiado optimistas porque en el resto del ano no podemos vivir de espejismo. Mayor favor nos hariamos con una concertación constructiva y correctiva ${ }^{5}$.

4) Las políticas monetarias y del crédito se han ajustado a los objetivos del programa monetario, a la contención de la inflación, al sostenimiento del tipo de cambio, al apoyo del ahorro con intereses más realistas y a la reconducción del crédito hacia los sectores productivos. El manejo de todas las medidas técnicas aplicadas en el presente ano se enmarcan en un proceso de transición de banca nacionalizada a banca privada. Mucho se ha escrito y discutido en sucesivos seminarios sobre este tema que seguirá siendo punto de agenda controversial mientras la mora y los morosos no queden en paz con Dios y con el sistema bancario. Sin regresar sobre estas discusiones vale la pena comentar brevemente los objetivos y los temores que subyacen en el proceso de la reforma monetaria.

En la mente de los progenitores la privatización bancaria es una reforma necesaria para poner un límite a la estatización politizada del crédito y a la improvisación de las medidas monetarias. Para quienes no son los progenitores de la reforma la privatización bancaria suena a to que en nuestro pais significa privatización, es decir concentración bancaria y concentración del crédito. Debajo de las palabras se esconde una historia algo alejada de la terminologia. En la década pasada se calificó a la banca de nacionalizada, cuando en realidad se vió totalmente desnacionalizada por una absorción de la coyuntura internacional, por la sangria del gasto de guerra, por la cuantiosa fuga de capitales privados y por un elevado monto de mora y de morosos afiliados a la gran empresa. Siendo asi la historia, a la banca nacionalizada la podemos describir como banca privada de capitales por los de dentro y los de fuera. Este comentario no disculpa las deficiencias

5. Montoya Aquiles: "La concertación nacional: una necesidad impostergable". ECA. Septiembre, 1990; pp. 747-758. 
de su administración y no disimula la necesidad de una profunda reestructuración'.

Tampoco se puede admitir que la privatización, por oposición de contrarios corrige ipso-facto los desperfectos inculpados a la banca nacionalizada. Otro tipo de politización y de concentración del crédito así como deficencias técnicas en los Indices internos bancarios coexistieron en las décadas de la banca privada; la ley del péndulo puede llevarnos otra vez a similares desviaciones sociales en el destino del crédito ${ }^{7}$. Aun no se ha acabado de reestructurar toda la cúpula administrativa, funciones de las autoridades monetarias, régimen de tiempos y nombramientos de presidentes y directivos donde el riesgo de nueva politización puede esconderse, y queda por esclarecerse el juicio contra la mora y los morosos.

Lo importante de todas estas discusiones es que nos acercan y nos enfrentan con los problemas técnicos del manejo monetario de nuestros dineros, en moneda nacional y en reservas netas de divisas, buscando el diffcil equilibrio de frenar la inflación y reanimar el empleo através de un crédito rentable a la institución bancaria y social para el conjunto de la nación. Hay que decir que lograr todo esto en un breve período no es fácil y al optar entre las diversas alternativas siempre habrá quienes aplaudan y quienes protesten y corrijan. Por ello es necesario que se prolonguen estos análisis y discusiones sobre el proceso monetario. El tema interesa al académico y al hombre de la calle.

El sector monetario doméstico en 1990 se ha visto protegido por el incremento de las reservas internacionales netas, antes comentadas, y sostenido desde dentro por una acumulación de depósitos bancarios, sobre todo del cuasi-dinero. El hecho de que los depósitos a la vista y el cuasi-dinero se hayan incrementado a un ritmo mayor que el numerario en poder del público se interpreta como una mayor confianza en el sistema bancario. La interpretación es razonable; pero también existen quienes no tienen tal confianza porque no tienen capacidad de hacer depósitos o no esperan que a ellos se les concedan los créditos. Bajos cualquier hipótesis es un dato estadistico el incremento de los depósitos (Cuadro 6), así como es cierto que el público se pregunta en

6. DIES CENITEC: "EI sistema financiero de EI Salvador; análisis y perspectivas". CENITEC. Año-P mayo-1989.

Hem: "La reforma del sistema financiero: ¿es oportuna la reprivatización?" CENITEC. Vol. I; Ne 2. Agosto-septiembre, 1990.

7. Aróvalo Damas, et alii: "Anáisis comparativo de la banca privada y banca nacionalizada en El Salvador: 1971-1988". Tesis de Grado. UCA. Sept. 1990. 


\section{Cuadro 6}

Evoluclón de los medlos de pago' en términos reales

(Tasas de variación)

\begin{tabular}{lrrrrrrrrrr}
\hline & & M1 & & \multicolumn{2}{c}{ Cuasl-dinero2 } & \multicolumn{2}{c}{$\begin{array}{c}\text { M2 (M1 + } \\
\text { Cuasl-dinoro) }\end{array}$} \\
& 1988 & 1989 & 1990 & 1988 & 1989 & 1990 & 1988 & 1889 & 1990 \\
\hline Enero-Marzo & -0.6 & -6.0 & -2.3 & 0.1 & 3.1 & 2.2 & 0.2 & 4.1 & 0.5 \\
Enero-Junio & -18.6 & -13.8 & -10.3 & -3.9 & -6.9 & 5.5 & -8.3 & -9.3 & -0.3 \\
Enero-Septiembre & -22.2 & -20.1 & -11.3 & -1.1 & -8.1 & 10.1 & -8.8 & -12.3 & 2.2 \\
\hline
\end{tabular}

Fuentes: GAES-MIPLAN.

1/ Excluye depósitos del gobierno central

2/ Incluye depósitos de ahorro, a plazo y en divisas

cuál de los bancos los depósitos estarán más seguros. También el BCR hace diferencia de tratamiento y de control de liquidez entre bancos con mayor y menor solvencia financiera. El balance monetario del sistema bancario integra instituciones con dispares indices de rentabilidad y liquidez, estando pendientes algunas fusiones bancarias. Por ello la autoridad monetaria, al mismo tiempo que inyecta liquidez a las instituciones con seria crisis financiera, vigila para que el conjunto del sistema no presione sobre la inflación por extralimitación del crédito.

Aunque la base y la oferta monetarias han mantenido ritmos crecientes "el crédito total del sistema financiero consolidado en el trimestre se ha reducido en $0,8 \%$, comparando los saldos de septiembre y junio. Más notable es la reducción experimentada del 1,5\% en el crédito al sector privado. Lo anterior implica que otros rubros tienen que explicar el destino de los recursos captados. Los bancos aumentaron sus depósitos en el BCR y ha aumentado su adquisición de bonos del $\mathrm{BCR}^{\prime \prime}$. Aunque este párrafo hace referencia al tercer trimestre, deja traslucir un conjunto de medidas monetarias aplicadas a to largo del ano. Es de esperar que se incremente el crédito al sector privado en los tres meses finales por ser un trimestre de mayor actividad económica y expansión crediticia, a menos que los recursos se obtengan por canales informales o por autofinanciación.

El crédito del sistema bancario al Gobierno Central y al sector privado se ha mantenido en los límites del programa monetario, y la reducción del crédito interno total ( $\$ 390$ millones) obedece a la contracción del crédito al resto del sector público ( -400 millones); ello se ex-

8. FUSADES: "Informe Económico Semanal". № 31; 12-11-1990. 
plica por una mejor situación financiera de las instituciones autónomas en su conjunto, luego de los ajustes en las tarifas de servicios públicos y mejor administración de sus recursos. Aunque los datos se refieren a los nueve primeros meses del ejercicio traducen el lineamiento de las medidas emprendidas desde el pasado ano. Por su parte, los depósitos relacionados con donaciones de AID sirven a financiar proyectos de inversión pública y de servicio social, asf como otros programas sociales ejecutados por instituciones no gubernamentales.

EI BCR, en cuanto autoridad monetaria y banco de bancos, ha ajustado la concesión del crédito a los límites del programa monetario de modo que el incremento de los depósitos bancarios no ponga en peligro el control de la inflación. Asi el BCR redujo el crédito, en los nueve primeros meses, a los bancos comerciales en $\$ 155$ millones por debajo del monto programado, combinando dos operaciones de signo contrario. A cuatro de los bancos intervenidos por su critica situación financiera se les hicieron créditos por valor de $₫ 327,7$ millones para apoyar el crédito al sector privado; mientras que el mismo BCR coloo ๔592 millones en bonos de estabilización entre los bancos con mejor solvencia financiera, a fin de esterelizar una parte del rápido crecimiento de los medios de pago y ajustar el crédito a los limites del programa monetario. (GAES; p. 74). Con ello se está buscando que el sistema bancario mantenga los límites adecuados de encaje legal y del coeficiente bruto de liquidez.

Este recuento de algunas de las politicas y medidas apegadas al programa monetario del BCR y a los lineamientos del modelo económico nos deja entrever que nos hallamos en un proceso de reestructuración de todo el sistema bancario y de la reorientación del crédito: menos hacia el sector público, más hacia el sector privado productivo. La autoridad monetaria está empenada en un doble abanico do problemas dentro y fuera del mismo sistema bancario. La primera constatación general es que el mercado monetario es un "mercado-politizado", en el sentido de regulado y que no puede abandonarse a los impulsos del laissez-faire. El nivel de reservas internacionales netas puede afectar el nivel del circulante interno, y el BCR tiene que hacer el papel de esclusa reguladora. El monto de depósitos puede distorsionar el flujo del crédito y habrá que combinar medidas de apoyo o de esterilización de liquidez. En el presente ejercicio se aprecian estas maniobras técnicas cuando el control de la inflación, prioridad principal, hay que realizarlo en una fase de reacomodación bancaria, cuando el balance monetario general esconde serias diferencias del solvencia financiera entre estas instituciones dentro de una crisis generalizada. 
El saneamiento y la reestructuración del sistema tomará su tiempo, asi como la reorganización de funciones adscritas a las instituciones que ejerzan la autoridad monetaria en conexión, pero con la debida independencia, del Gobiemo Central. Este proceso de reestructuración es necesario independientemente de que se trate de banca privada 0 nacionalizada, o banca mixta en el doble sentido de esta expresión; como el proceso tomará su tiempo será tema de evaluación a lo largo de 1991, al igual que la controversial mora y develación de los morosos.

El otro abanico de problemas se centra en el usuario del crédito y en los propios criterios del crédito. En anterior publicación to hemos comentado bajo el acápite de "crédito social con capital privado"s. Dada la crítica situación de las instituciones financieras es lógico que éstas busquen la rentabilidad monetaria que asegure dividendos internos, solidifique el patrimonio pasivo y muestre solvencia ante los depositantes. Por ello se hablará de hacer crédito productivo. Sin embargo, desde un criterio social habria que preferenciar el crédito reproductivo, es decir el dirigido a sectores dinamizantes de otros sectores económicos como mayores demandantes y oferentes de insumos o como mayores generadores de empleo. Este criterio es importante en un momento y en una perspectiva en que la política monetaria está más centrada en contener la inflación que en activar directamente el empleo. Otra razón avala este temor: el costo del crédito por elevación de los intereses activos que discrimina la distribución del crédito. El informe sobre "Clima de Negocios y Actividad Económica" de FUSADES constata to que se deja escuchar en los medios de comunicación social. Mientras que la grande empresa muestra cierto dinamismo de actividad económica (IVAE), la pequeña y microempresa, estabilizadas en un $46 \%$ de su capacidad instalada, enumera entre los factores restrictivos la falta de acceso al crédito bancario, que para la gran empresa es citado como uno de los factores dinamizantes ${ }^{10}$.

Si los representantes de la pequeña empresa han dejado oir su voz a lo largo del año, al finalizar el presente ejercicio y de cara a 1991 nos presentan una evaluación global del modelo económico y de las políticas aqui comentadas. Mientras que para el representante de la Cámara de Industria y Comercio el modelo ha funcionado bastante bien en 1990 y se espera camine mejor en 1991, la Asociación de Medianos y Pequehos Empresarios Salvadoreños (AMPES) presenta a consideración del gobierno y de la nación un análisis y un pronunciamiento más

9. Ibisate Fco. Javier: "La ley de privatización bancaria; ¿de la privatización a la privatización?". Realidad Económico-Social, No 16; julio-agosto, 1990.

10. FUSADES. "Clima de negocios y actividad económica "Trimestre-III, 1990. 
realista. "El modelo que queremos. Dentro del complejo contexto en que se desarrolla nuestra economla, se hace más necesario fijar un ordenamiento que ayude al desarrolllo económico del pais. Esto nos obliga a plantearnos con seriedad un Modelo Econórnico que empuje con decisión la equidad y el crecimiento como elementos fundamentales, lo cual sólo puede plantearse dentro de un esquema de Economia Social de Mercado que garantice realmente la libre competencia y no permita la formación de monopolios y oligopolios dentro de un mercado en el cual el más grande destruye al más pequeno porque las oportunidades no son las mismas para todos ...Pensar que el mercado puede gobernarse completamente sólo es una equivocación sumamente seria y que traerá consecuencias para nuestra economía y por ende para todos los salvadorehos ...Basados en la encuesta "Clima de Negocios", donde se senala que las ventas del pequeno empresario han tenido una merma del $6 \%$ y los micros de un $7 \%$ negativo, que no guardan relación con el incremento habido en los sectores más grandes, confirmamos que: 1) al hablar de dinamismo de la economia, se refieren sólo a las grandes empresas. 2) Las pequenas y microempresas no son factores tomados en cuenta seriamente a la hora de trazar políticas económicas reales. 3) Dentro de las prioridades del Gobierno, los micro y pequenos empresarios no tienen un valor económico, tal vez sólo electoral. 4) El acceso al crédito de los pequenos empresarios se volverá más difícil con la privatización de la Banca, toda vez que en aras de la captación de divisas las prioridades crediticias irán a los agroexportadores no tradicionales y tradicionales con la sana lógica de la eficiencia financiera, relegando a los bancos de fomento y a la ayuda internacional otras responsabilidades crediticias. 5) Si consideramos que gran parte de la producción de los micro y pequenos empresarios es de consumo nacional y popular, y aun cuando generan riqueza no generan divisas, será difícil que los escasos recursos crediticios tengan prioridad para ellos, quienes en el mejor de los casos recibirán el excedente de los mismos. Nuestras sugerencias... El Gobierno de la República, a nuestro juicio, para demostrar su voluntad de fortalecimiento del sector privado, deberá garantizar que no existirán sólo privilegios para unos y cargas sólo para otros sectores de la economia. Además deberá definir una política económica que permita la verdadera integración de la pequena y mediana empresa para lograr esa equidad e igualdad de competencia que se menciona en la Economia Social de Mercado... En conclusión, si no hay un cambio de actitud hacia el pequeno y microempresario por parte del Gobierno, nosotros vislumbramos un ano 1991 bastante sombrio para el sector que representamos, que progresivamente se irá debilitando manteniendo una econo- 
mía de subsistencia y baja competitividad. La Asociación de Medianos y Pequenos Empresarios Salvadorenos, AMPES, considera que no sólo un cambio en el Programa Económico del Gobierno es suficiente, sino que más importante aún es lograr la concertación nacional al más corto plazo posible... Exhortamos al FMLN, a las Fuerzas Amadas y sectores políticos, anteponer las verdaderas aspiraciones e intereses de la Patria, corresponsabilizándose de una vez por todas para construir una nueva sociedad donde la concordia, equidad y justicia sean consecuencia de una verdadera democracia participativa, respetuosa de los derechos humanos"11

Esta cita navidena, algo larga, vale más que muchas reflexiones académicas, porque recoje la experiencia real del más numeroso sector productivo, amplia escuela de aprendizaje profesional y relativamente mayor generador de empleo. Los análisis macroeconómicos globales, que en su publicidad utiliza el Gobiemo, esconden grandes desigualdades en los resultados y en las consecuencias. El temor generalizado es que no se apliquen oportunamente las medidas de compensación social para equilibrar los efectos adversos sociales de un modelo de economía de mercado que no se vislumbra aún como social para los más pobres de los pobes. La segunda parte del Plan de Desarrollo Social quisiera ir en este sentido, pero se trata de una segunda parte, subimperio del Estado supeditado a una función subsidiaria. Como al mismo nivel gubernamental se siente la dificultad de servir a dos senores, al mercado y a los pobres, se están impulsando otras líneas de acción; tal es el objetivo del Fondo de Inversión Social de EI Salvador (FISS), que tiene el mérito de reconocer la importancia y gravedad del problema". Dentro de la estructura del sector público no existe ninguna institución de acción directa integral para combatir efectivamente la condición de pobreza. En la actualidad existen centenares de dependencias públicas, organizaciones no gubenamentales y agnupaciones comunales que realizan numerosos proyectos entre los pauperizados en forma descordinada. Se requiere un instrumento que medie entre la capacidad captadora de recursos del Estado y la enorme posibilidad realizadora de las instancias locales. Ese papel le corresponde al Fondo de Inversión Social de El Salvador. El Fondo captará principalmente recursos de origen externo, permitiendo su transferencia directa a la capitalización social, comunal y humana de proyectos de atta rentabilidad social, focalizados en los grupos pobres más vulnerables. EI

11. AMPES da a conocer el Modelo Económico que desea. El Mundo: 27-1290. 
Fondo concederá sus recursos bajo la modalidad de transferencias no reembolsables..." (GAES; pp. 118-119).

Testimonio interesante por sus objetivos y por to que explicitamente reconoce al hablar de sus objetivos: "Compensar a la población en situación de pobreza por los efectos de ajuste estructural"... (p. 118) Aqui se puede hacer una reflexión: las cuantiosas remesas de nuestros emigrantes, los "pobre-dólares" colaboran tanto como las exportaciones tradicionales al éxito del ajuste estructural, pero el modelo del ajuste estructural no devuelve la deuda pensando en aliviar la suerte de los pobres. ¿Les ha beneficiado la marcha de la inflación y del empleo?

\section{5) Anállsis y expectatlvas acerca de la Inflaclón y empleo}

Los análisis y expectativas referidos a la inflación y el empleo presentados en los informes gubernamentales y afines (FUSADES) son excesivamente cortoplacistas y peligrosamente gloriosos y partidistas: pequenas contracciones coyunturales dentro del alza generalizada de los precios, fruto en parte de las buenas cosechas, son interpretados como logros del modelo e indices del cambio de tendencias. Una perspectiva de más largo plazo nos obligan a decir que la inflación y el desempleo viene golpeando hasta la inanición a los gnupos sociales más desposeidos. Para la población en general estas dos variables se integran y refuerzan el grado de empobrecimiento generalizado. Por un lado la inflación reduce el poder real de compra familiar, y el desempleo diezma el origen del mismo poder de compra. En la generación del proceso de pobreza se suman ambas acciones depredadoras del ingreso.

En el análisis y en la aplicación de las políticas económicas la inflación y el empleo son consideradas como dos objetivos relativamente contrapuestos (curva de Philips) de suerte que puede reducirse la inflación sacrificando cierta tasa de empleo y viceversa. Como esta contraposición se ha venido acentuando en las dos últimas décadas de estanflación, los gobiernos se ven obligados a optar por determinada alternativa: más de uno y menos del otro. Como el empleo constituye el origen de los ingresos, los partidos aspirantes al poder programan y prometen empenarse en la generación de nuevos empleos; esto atrae el voto de desempleados-subempleados. Pero una vez en el poder, presionados por el mecanismo del mercado internacional, pasa a primer término la preocupación por contener la inflación, relegando el empleo a un mediano plazo. La razón es obvia: la inflación reduce y dificulta la capacidad de exportar e incrementa el atractivo por las importaciones, deteriorando el tipo de cambio y originando una con- 
tracción productiva interna compensada por las importaciones. Como la inflación por costos de oferta es más difícil de corregir en el corto plazo, el énfasis se concentra en las posibles causales de inflación por demanda. Pronto se descubren dos causales: la demana del Estado en sectores menos productivos (suelen seleccionarse sectores sociales) y la presión de los salarios que al mismo tiempo son costos de producción. Por lo tanto, dada la dificultad de constrenir los costos de capital, las políticas económicas y las presiones sobre los sindicatos buscan contener los gastos en trabajo, la demanda salarial y las inversiones sociales del Estado, para mejorar la capacidad competitiva.

Una aplicación de estas teorias y politicas la experimentamos directamente en 1982-84 con el programa de estabilización y el decreto 544, que trataron de congelar precios y salarios, aunque los precios se salieron del freezer. Por razones semejantes, aunque presentadas con otro envoltorio, el actual modelo de estabilización y ajuste estructural se concentra primordialmente en contener la inflación, apoyándose en una política cambiaria más realista, en orden a incrementar las exportaciones, reducir las importaciones subsidiarias $y$, con un tiempo de espera, hacer atractiva la llegada de ahorro e inversión extranjera. Siendo ellos objetivos convenientes, en nuestra situación de economía tan abierta y dependiente, las medidas de contención de la inflación interna dificultan la generación de empleo al encarecer sensiblemente el costo nacional de las importaciones, sobre todo las importaciones de capital. Se da a la vez otro círculo vicioso; la productividad del trabajo será baja, y también su remuneración, por ser baja la productividad del capital relativamente obsoleto. Por su parte el empleo no puede crecer sensiblemente, como lo confirman las actuales encuestas de clima de los negocios, mientras que el alza de costos presentes, las expectativas de los costos futuros y los intermediarios presionan al unisono sobre el alza de los precios. Esta es nuestra compleja situación, que de momento no augura demasiados optimismos y más vale no dejarse llevar de espejismos.

Hay un elemento que no es mencionado en los informes oficiales como uno de los frenos al mayor auge de la inflación; para aceptarlo hay que mirar la historia desde un mediano plazo. Si desde 1973 y sobre todo a partir de 1980 la inflación ha venido erosionando el poder de compra a un ritmo mayor que el alza crónica de los salarios, si el desempleo-subempleo ha afectado a casi dos tercios de la población laboral, necesariamente hay un elemento que se ha contraido y es la demanda salarial. Si los precios no han subido más tenemos que buscar parte de la explicación en la conjunción de inflación más desempleo: la misma pobreza frena el crecimiento de la inflación por retiro del 


\section{Cuadro 7}

Indice de precios al consumidor: primer semestre 1988-1990

(Porcentaje de variación)

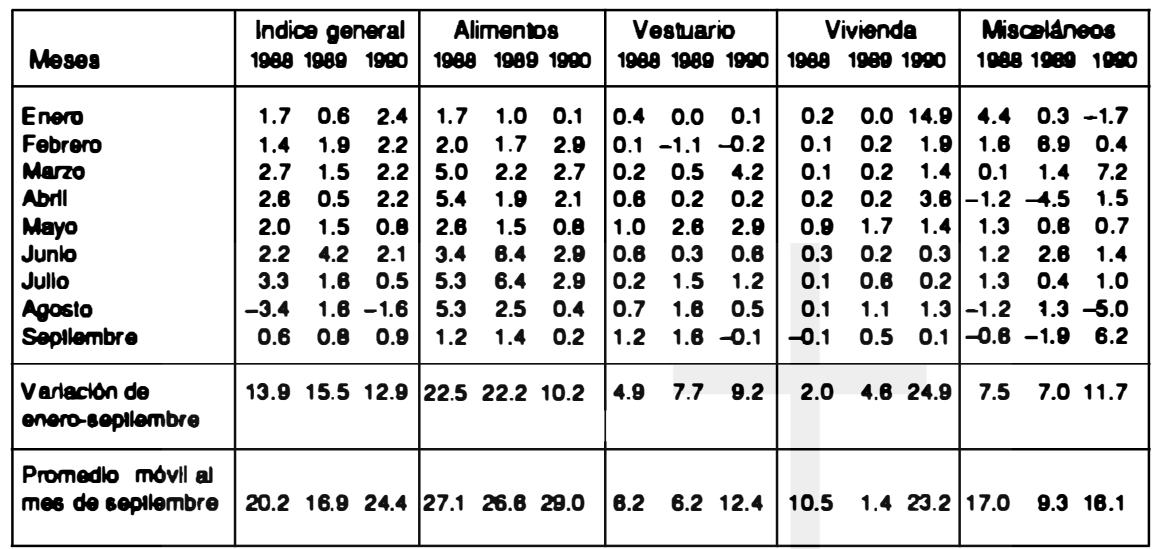

Fuente: Dirección General de Estadlstica y Censos, y Grupo Asesor Economico y Sodal-Ministerio de Planificación.

mercado o transferencia a un mercado informal de bienes inferiores. La historia se ha adelantado a las políticas: no es que haya que reducir la demanda para reducir la inflación, sino que la demanda potencial, contraída por largos anos de inflación y desempleo, ha ido frenando el ritmo creciente de la inflación. La explicación es tanto más cierta si recordamos que la inflación es discriminante (guerra civil monetaria) beneficiando a quienes tienen capacidad de trasladar el alza de costos al alza de precios, es decir capacidad de hacer inflación para defenderse de la inflación, mientras que depreda a los titulares de simples salarios y escuetas jubilaciones, peor aún a los desempleados.

Aunque es una buena noticia el que se haya contraido en los últimos meses el ritmo de la inflación, con todo el análisis publicitario es demasiado cortoplazista e imperfecto. Ya hemos visto, por ejemplo, que el sector construcción ha sufrido un sensible receso y que sus insumos encarecidos están afectando los precios y alquileres de la vivienda, bien típico social. Por lo que toca al rubro de los alimentos se puede apreciar que el indice de precios al consumidor (IPC) evoluciona en torno a los precios de los alimentos, dada su importancia en la canasta familiar y dada la dependencia que tienen los granos básicos de las buenas o malas cosechas. Puesto que en el pais no ha existido desde antiguo una política de "seguridad alimentaria" (Proceso, Nos. 434, 440, $451,452 \ldots$ los precios de los granos básicos, y por ende de los alimentos, se ven sometidos a fuertes oscilaciones, más sensibles en 
hogares de menores ingresos. Debido a las buenas cosechas de 1990, los precios de los alimentos han reducido su ritmo de alza, a partir del tercer trimestre, algo por debajo del IPC (Cuadro 7). Pero no fue asl en los meses y anos anteriores. El problema se aprecia más realistamente mirando un simple dato desde el mediano plazo. Tomando el mes de diciembre de 1978, ano base $=100$, el Indice general de precios al por menor o consumidor se eleva a 741,9 para julio de 1990, y el índice de precios de los alimentos era de 912,1 en la misma fecha. No vamos a decir que ninguno de los salarios ha subido en tal proporción porque esta frase suena ya a humor negro, pero también suena a fina ironia decir que 1991 será el ano de la recuperación porque el modelo ya está dominando la inflación. Queda además por comprobar honestamente otro detalle: ¿la inflación de 1990 ha afectado a las clases populares sólo en un 20\%? Porque las contabilidades domésticas parecen resentirse de un voltaje mayor.

No vamos a pedir al Gobierno-Arena que en año o año y medio cambie y reestructure una tendencia tan adversa, sobre todo si se bo confía a nuestro mercado liberalizado; pero sl podemos pedirle que no nos quiera hacer creer que la situación ya ha cambiado y que estamos entrando en la recuperación económica. Esto está bien para las tarjetas de Feliz Ano Nuevo, pero la realidad es algo más seria. Veamos, como botón de muestra, la situación del mercado laboral urbano de acuerdo a la reciente Encuesta de Hogares de Propósitos Múltiples, apartado cuarto: "empleo y previsión social" (GAES: pp. 106...) La encuesta se refiere al mercado laboral urbano y se presentan datos comparativos entre 1988 y 1990. Más que las cifras globales referidas a la "población en edad de trabajar (PET: de 10 anos para arriba!) y a la "población económicamente activa" (PEA: que tiene trabajo o lo buscan) nos interesan los componentes de estas poblaciones laborales.

Entre 1988 y 1990 se incrementa la población en edad de trabajar $(1,657.282$ - 1,787.896) y la población económica activa (PEA) (790.568 - 982.802), mientras que disminuye la población económicamente inactiva (PEI: estudiantes, amas de casa, jubilados-pensionados...), (Cuadro 8), que se explica oficialmente por mayor incorporación de la mujer al trabajo y que también se puede explicar por la necesidad de traer más sueldos a la casa. La Encuesta de Hogares nos brinda una serie de datos bien signiticativos. El mayor crecimiento relativo de la PEA urbana se localiza en las personas más jóvenes; el grupo de 10-14 anos creció en un 116,5\%. (Véase cuadro 8) ¿Qué hay de la escolaridad y formación personal de estos ninos y a qué se debe el hecho? El grupo de sesenta anos y más creció en un 38,9\%; con razón dicen que la inflación genera una eutanasia de los jubilados, 


\section{Cuadro 8 \\ Mercado Laboral Urbano \\ (Número de Habltantes y Tasas Porcentuales) \\ AÑOS 1988 - 1990}

\begin{tabular}{|l|r|r|}
\hline & $\begin{array}{c}1988 \\
\text { (enero-Junlo) }\end{array}$ & \multicolumn{1}{|c|}{$\begin{array}{c}1990 \\
\text { (enero-junlo) }\end{array}$} \\
\hline Población en Edad de Trabajar (PET)' & $1,657.282$ & $1,787,896$ \\
Población Económicamente Activa (PEA) & 790,568 & 982,802 \\
Población Ocupada & 716,473 & 884,921 \\
Población Subocupada & 395,580 & 480,363 \\
Subocupados Visibles & 93,210 & 90,647 \\
Subocupados Invisibles & 302,370 & 389,516 \\
Población Plenamente Ocupada & 320,893 & 404,558 \\
Población Desocupada & 74,095 & 97,881 \\
Cesantes & 50,127 & 72,735 \\
Buscan Primera Vez & 23,968 & 25,146 \\
Población Económicamente Inactiva (PEI) & 866,714 & 805,094 \\
Estudiantes & 418,329 & 409,769 \\
Amas de Casa & 326,826 & 275,467 \\
Jubilados y Pensionados & 16,573 & 17,823 \\
Incapacitados & 76,444 & 86,994 \\
Otros & 28,542 & 15,041 \\
Tasa de Participación (PEA/PET) & $47.7 \%$ & $55.0 \%$ \\
Tasa de Ocupación & $90.6 \%$ & $90.0 \%$ \\
Tasa de Subocupación & $50.0 \%$ & $48.9 \%$ \\
Tasa de Ocupación Plena & $40.6 \%$ & $41.2 \%$ \\
Tasa de Desocupación Abierta & $9.4 \%$ & $10.0 \%$ \\
Tasa de Cesantía & $6.3 \%$ & $7.4 \%$ \\
Tasa de Inactividad (PEI/PET) & $52.3 \%$ & $45.0 \%$ \\
\hline
\end{tabular}

Fuente: Encuesta de Hogares/MIPLAN.

1. Población de diez años y más.

quienes para sobrevivir tienen que regresar al trabajo. Aunque el mayor crecimiento absoluto se da en el grupo de 20-30 anos la evolución antes mencionada en ambos extremos pone de manifiesto la presión de la inflación en los hogares nacionales.

En el crecimiento de la población económicamente activa influye más el aumento del empleo femenino (34,6\%) que el del empleo masculino $(17,1 \%)$ dando lugar a diversas explicaciones sobre la mayor incorporación de la mujer al trabajo. El incremento de la población económicamente activa es significativamente mayor en la economia in- 
formal que en la economia formal, de suerte que cambian sensiblemente dichas proporciones. En 1988 un $62,5 \%$ se situan en el sector moderno y sólo un $37,5 \%$ en el sector informal; en 1990 cambian las proporciones: $47.6 \%$ en el sector moderno y $52,4 \%$ en la economia informal (veáse cuadro 9) Estas transferencias tienen un impacto en el

\section{Cuadro 9}

Poblaclón Económicamente Actlva Urbana por sexo, según rama de Actlvidad Económlca

(Número de personas)

\begin{tabular}{|c|c|c|c|c|c|c|}
\hline \multirow[b]{3}{*}{ RAMA DE ACTIVIDAD } & \multicolumn{4}{|c|}{$\begin{array}{c}\text { AÑOS } 1988-1990 \\
\text { SECTOR MODERNO }\end{array}$} & & \\
\hline & \multicolumn{2}{|c|}{ TOTAL } & \multicolumn{2}{|c|}{ MASCULINO } & \multicolumn{2}{|c|}{ FEMENINO } \\
\hline & 1988 & 1990 & 1988 & 1990 & 1988 & 1890 \\
\hline $\begin{array}{l}\text { Agricultura } \\
\text { Minería } \\
\text { Industria } \\
\text { Elec., Gas, Agua } \\
\text { Construcción } \\
\text { Comercio } \\
\text { Transp. y Comunic. } \\
\text { Establec. Financ. } \\
\text { Servicios } \\
\text { No bien especif. }\end{array}$ & $\begin{array}{r}43,954 \\
258 \\
100,388 \\
5,070 \\
35,408 \\
59,490 \\
25,740 \\
21,809 \\
146,033 \\
23,968\end{array}$ & $\begin{array}{r}36,485 \\
516 \\
106,654 \\
5,426 \\
31,164 \\
62,811 \\
22,185 \\
22,743 \\
153,453 \\
0\end{array}$ & $\begin{array}{r}34,464 \\
258 \\
66,341 \\
4,871 \\
34,168 \\
33,647 \\
21,889 \\
13,124 \\
94,334 \\
13,345\end{array}$ & $\begin{array}{r}27,720 \\
418 \\
69,891 \\
5,148 \\
29,526 \\
35,767 \\
19,681 \\
14,025 \\
92,214 \\
0\end{array}$ & $\begin{array}{r}9,490 \\
0 \\
34,047 \\
199 \\
1,240 \\
25,843 \\
3,851 \\
8,685 \\
51,699 \\
10,623\end{array}$ & $\begin{array}{r}8,765 \\
98 \\
36,763 \\
278 \\
1,638 \\
27,044 \\
2,504 \\
8,718 \\
61,239 \\
0\end{array}$ \\
\hline Total & 462,118 & 441,437 & 316,441 & 294,390 & 145,677 & 147,047 \\
\hline
\end{tabular}

SECTOR INFORMAL'

\begin{tabular}{|l|r|r|r|r|r|r|}
\hline & \multicolumn{2}{|c|}{ TOTAL } & \multicolumn{2}{c|}{ MASCULINO } & \multicolumn{2}{c|}{ FEMENINO } \\
\hline RAMA DE ACTIVIDAD & 1988 & 1990 & 1988 & 1990 & 1988 & 1990 \\
\hline Agricultura & 26,044 & 43,727 & 24,916 & 39,595 & 1,128 & 4,132 \\
Mineria & 84 & 218 & 84 & 218 & 0 & 0 \\
Industria & 63,864 & 106,491 & 34,588 & 50,142 & 29,276 & 56,349 \\
Elec., Gas, Agua & 166 & 412 & 166 & 334 & 0 & 78 \\
Construcción & 16,798 & 32,376 & 16,603 & 31,871 & 195 & 505 \\
Comercio & 122,848 & 190,826 & 34,177 & 57,615 & 88,671 & 133,211 \\
Transp. y Comunic. & 16,176 & 28,446 & 15,953 & 27,760 & 223 & 686 \\
Establec. Financ. & 798 & 2,147 & 719 & 1,173 & 79 & 974 \\
Servicios & 30,595 & 55,214 & 19,624 & 31,272 & 10,971 & 23,942 \\
No bien especif. & 0 & 25,184 & 0 & 8,421 & 0 & 16,763 \\
\hline \multicolumn{1}{|c|}{ Total } & 277,373 & 485,041 & 146,830 & 248,401 & 130,543 & 236,640 \\
\hline
\end{tabular}

1. No icluye Servicio Doméstico

Fuente: Encuesta de Hogares/MIPLAN. 
nivel de ingreso al generar niveles diversos de ocupación. La población económicamente activa (PEA-1990: 982,802) se divide en población ocupada (884.921) y población desocupada (97.881): cesantes o que buscan por primera vez, y que en 1990 superan la cifra de 1988 (74.095). Para nuestro análisis económico es dato muy significativo que dentro de la población ocupada (864.921), más del $50 \%$ es población subocupada (subocupados visibles o invisibles $=480.363$ ), superando el número de los plenamente ocupados (404.558). Tenemos asi que un elevado porcentaje de la población económicamente activa recibe salarios inferiores a los salarios mínimos en la propia área urbana, sin referirnos al campo. Efecto presente de consecuencias futuras es que la tasa de población laboral cubierta por algun sistema de seguridad social (ISSS.INPEP...) se redujo del $33,6 \%$ de la PEA urbana en 1988 al $29,3 \%$ en 1990 (Cuadro 10).

\section{Cuadro 10}

Población urbana ocupada cublerta por algún slstema de penslones y segurldad soclal) (Cifras absolutas y porcentajes sobre la PEA)

Años 1988-1990

\begin{tabular}{|l|r|r|r|r|r|r|}
\hline & \multicolumn{2}{|c|}{ TOTAL } & \multicolumn{2}{c|}{ MASCULINO } & \multicolumn{2}{c|}{ FEMENINO } \\
\cline { 2 - 7 } & 1988 & 1990 & 1988 & 1990 & 1988 & 1990 \\
\hline \multirow{2}{*}{ Total } & 265,280 & 287,526 & 174,097 & 183,881 & 91,183 & 103,645 \\
& 33.6 & 29.3 & 37.5 & 33.9 & 27.9 & 23.6 \\
Sector Moderno & 258,263 & 273,899 & 170,476 & 175,807 & 87,787 & 98,092 \\
& 55.9 & 62.0 & 53.9 & 59.7 & 60.3 & 66.7 \\
Sector Informal' & 7,017 & 13,627 & 3,621 & 8,074 & 3,396 & 5,553 \\
& 2.1 & 2.5 & 2.5 & 3.2 & 1.9 & 1.9 \\
\hline
\end{tabular}

1. Incluye Servicio Doméstico

Fuente: Encuesta de Hogares/MIPLAN

El informe oficial del GAES-MIPLAN (p. 113) senala tres factores explicativos a esta situación laboral. La agresión terrorista de noviembre-diciembre 1989 por destrucción de la infraestructura; los movimientos migratorios hacia el área metropolitana y el "aún escaso impacto sobre el empleo formal de los brotes iniciales de reactivación económica... El lector juzgue sobre el valor de las explicaciones. Si el modelo no ha tenido hasta el momento un efecto sobre el empleo se reconoce que sí lo ha tenido en otra dirección". Finalmente, la Encuesta de Hogares nos proporciona información acerca de la evolución que ha 
experimentado la distribución del ingreso en nuestro país durante lus dos últimos anos. Desde finales de 1988 se detecta una redistribución del ingreso de las áreas urbanas en favor de las personas que tienen mayores ingresos en perjuicio de quienes se ubican en los estratos medios y bajos de ingreso. Este fenómeno tiene como causas principales la inflación y la pérdida de valor de la moneda, herencia de la pasada gestión gubemamental" (p. 115).

Una vez más hay que lamentar que a problemas tan serios se den explicaciones tan partidistas, tan cortometristas y tan inaceptables. En los pasados anos y décadas de imperio de la simple economla de mercado ya existian estas injustas e injustificables diferencias de ingresos. La curva de Lorenz o distribución porcentual de la Renta 1976, 1977 nos indicaba que el $62,9 \%$ de la población de menores ingresos disponia sólo del $28,7 \%$ de la R.N., mientras que el $6,2 \%$ de las familias con mayores ingresos se apropiaba de un monto semejante, $28,3 \%$. $Y$ treinta anos antes, 1945-1946, nos encontramos con proporciones similares: el $60 \%$ de la población percibia ingresos equivalentes el $32 \%$ de la RN. mientras que en el otro extremo el $5 \%$ de las familias con ingresos más altos percibia el $35,5 \%$ de la renta total ${ }^{12} \mathrm{EI}$ problema de la inflación, del empleo y de la pobreza en el área urbana y sobre todo en el área rural merecen explicaciones más serias y soluciones más serias que lo que pueda deducirse de las estadisticas de los cinco últimos meses y de las gestiones de uno u otro gobierno en los cinco últimos anos. Este tipo de explicaciones en nada ayudan al proceso de concertación y de coparticipación que es lo único que nos puede sacar del atolladero.

Por ello no deben extrañarse los progenitores del actual modelo que leamos con una mezcla de sonrisa y de pena párrafos como el que cierra el comentario a la Encuesta de Hogares-1990, párrafo por cierto un tanto contradictorio.

"A través del establecimiento de un sistema de Economía Social de Mercado se espera crear condiciones que faciliten oportunidades de empleo, mayores niveles de producción, una disminución progresiva de la inflación, la estabilización del valor de la moneda y una optimización del gasto gubernamental. De este modo y con el apoyo de programas sociales compensatorios focalizados hacia los grupos más vulnerables, se espera corregir el impacto inicial inevitable del programa de ajuste a

12. Sevilla Manuel: "Visión global sobre la concentración económica en EI Salvador". Boletín de CC. Económicas y Sociales. Mayo-junio, 1984; p. 159. 
fin de elevar los niveles de ingreso y calidad de vida de las capas medias y pobres de El Salvador (GAES; p. 115). El párrafo es un tanto contradictorio porque lo que sf se admite es el efecto inicial inventable regresivo sobre las capas de menores ingesos, y lo confirma la presemte encuesta (veáse cuadro 11). Lo que se espera es todo el resto en virtud de la misma economía social de mercado. Pero si "nuestra economla de mercado" fuera tan social, que nunca lo ha sido, no necesitarla de programas compensatorios sociales; más directamente, las grandes necesidades sociales deberlan ser objeto del mercado, si somos sociales, pasando de una economía social de mercado a una economia social con mercado ${ }^{13}$.

Hay otras razones para no poner nuestra fe en este párrafo futurista. Siendo este informe del GAES-MIPLAN un análisis económico y social del ano 1990 extrana que no se toque para nada el tema de la inseguridad civil, de la impunidad en la gestión y administración de la justicia, el diálogo sobre los derechos humanos, la imposición del militarismo sobre el civilismo y puntos de agenda nacionales que afectan directamente a la democracia económica y social. Tampoco son democráticos los principios filosóficos del modelo.

\section{Cuadro 11 \\ Distrlbuclón del Ingreso Famillar Mensual de los Hogares Urbanos por Declles}

ANNOS 1988-1990

\begin{tabular}{|c|c|c|c|c|c|c|c|c|c|}
\hline \multirow[b]{2}{*}{ DECIES } & \multicolumn{3}{|c|}{ HOGARES } & \multicolumn{3}{|c|}{ INGRESO PROMEDHO } & \multicolumn{3}{|c|}{$\begin{array}{l}\text { POACENTAE DE MOAESO } \\
\text { MECEDDO }\end{array}$} \\
\hline & 1908 & 1990 & 1000 & 1998 & 1900 & 1900 & 1908 & 1980 & 1900 \\
\hline Primero & 49.074 & 49.726 & 52.658 & 212.31 & 207.48 & 180.66 & 1.81 & 1.51 & 1.21 \\
\hline Sogundo & 49.074 & 49.726 & 52.858 & 430.45 & 424.85 & 408.29 & 3.74 & 3.08 & 2.73 \\
\hline Tercoro & 49.074 & 49.726 & 52.658 & 645.46 & 582.12 & 604.57 & 5.50 & 4.22 & 4.04 \\
\hline Cuano & 49.074 & 49.726 & 52.658 & 731.77 & 734.57 & 785.53 & 6.24 & 5.33 & 5.25 \\
\hline Quinto & 49.074 & 49.726 & 52.658 & 874.21 & 897.15 & 964.78 & 7.45 & 6.51 & 6.45 \\
\hline Sexto & 48.074 & 49.726 & 52.658 & $1,060.98$ & $1,091.88$ & $1,166.08$ & 8.04 & 7.92 & 7.79 \\
\hline Séptimo & 49.074 & 49.726 & 52.658 & $1,259.71$ & $1,359.77$ & $1,460.72$ & 10.74 & 9.87 & 9.76 \\
\hline Octavo & 49.074 & 49.726 & 52.858 & $1,468.54$ & $1,701.41$ & $1,867.93$ & 12.52 & 12.35 & 12.40 \\
\hline Noveno & 49.074 & 49.726 & 52.658 & $1,818.43$ & $2,314.22$ & $2,546.09$ & 15.50 & 16.79 & 17.01 \\
\hline DAcimo & 49.074 & 49.726 & 52.658 & $3,222.82$ & $4,467.20$ & $4,979.46$ & 27.40 & 32.43 & 33.28 \\
\hline
\end{tabular}

Fuente: Encuesta de Hogares/MIPLAN.

13. Ibisate Francisco Javier: "Economla social de mercado y economla social con mercado". ECA. Abril-mayo, 1989, 311-336. 


\section{Comenzamos a recuperarnos en 1990...}

Terminando por donde comenzamos, recordando que dicen que el siglo XXI se ha iniciado en 1990, aunque parezca extrano vamos entrando en esta línea de los europeos. No es que pongamos la fe en el cambiar para mejorar de inspiración neoliberal, sino porque se ha iniciado un debate sobre cuestiones civiles y sociales que caen fuera del radar de la economía de mercado. La lástima es que hay palabras e ideales que han sido manoseados por experiencias históricas no muy felices y da miedo usarlas o hay que buscarles un sustituto. Tal es el caso del ideal socialista, desfigurado por las lamentables experiencias que hoy llamamos socialismo-reales, para indicar lo contrario, socialismos-irreales o no-socialismos. O se acepta el error o hay que hablar de "solidaridad". En nuestro pais desde hace tiempo se usa el concepto e ideal de la democracia, pero la deficiente experiencia de un partido llamado democracia-cristiana, en una década turbulenta, ha devaluado el término hasta convertirlos en el chivo expiatorio de todas las calamidades actuales.

En nuestro caso ya le vamos encontrando sustitutos concretos al concepto de democracia. A lo largo de 1990 se viene hablando, en público, de los derechos humanos y en el acta de las sesiones del diálogo se concretizan muchos de estos derechos. Se habla de justicia, pero con un importante aditivo: la administración de la justicia civil y penal. Con ello sale a flote el tabú de la impunidad, detectado por observadores nacionales y extranjeros. Se trata de aplicarle la medicina más operativa en el corto plazo, el recorte de la ayuda externa, quedando en esperado suspenso el tratamiento de la depuración.

No sólo por razones de déficit fiscal, sino de déficit civil, casi todos están de acuerdo en un proceso de desmilitarización con el visto bueno de la Constitución, a imagen y semejanza de lo que vienen haciendo las grandes potencias. Esto significa un avance porque, tras larga experiencia, hemos comprendido que la guerra sólo nos lleva a la guerra y el terrorismo, lo cual es algo propio del pasado siglo- $\mathrm{XX}$. Otro avance hacia la democracia es que comenzaron dialogando sólo dos, con agenda abierta o tapada, y al terminar el ano no sólo se les pide que hablen claro, sino que escuchen y admiten a más grupos sociales en las sesiones del diálogo-negociación; se les pide que priorizen los deseos del pueblo, si quieren que se les considere representantes del pueblo y no de sus ideologías e intereses propios.

Se propone la concertación como necesidad impostergable ${ }^{14}$ y por

14. Montoya Aquiles. Item. ECA. Septiembre, 1990. pp. 747-757. 
ello se hace impostergable esta reflexión. La concertación ofrece los primeros frutos: las reuniones de la interpartidaria, aunque en algun punto concreto falle el pacto firmado. Esto es bien valioso por que nuestra historia política ensena que el partido, por definición, es algo partido con tendencia a partirse más y más. Lo que puede salvar a cada partido es la interpartidaria, porque unos aprenden de otros, sobre todo si logra que se hagan algunas fusiones como en el sistema bancario. $Y$ con la interpartidaria la intergremial y otras terceras fuerzas que ya son voz de los sin voz. Vamos entrando en una visión más estructural, más civil y más social de la democracia.

Haciendo un parangón (aunque toda comparación es imperfecta) así como nuestro Plan de Desarrollo admite que no puede lograr su primera parte, el desarrollo económico, sin una sensible compensación social, segunda parte, también en el ordenamiento civil se comienza a reconocer que no es posible gobemar unilateralmente sin la activa participación de quienes más deben mejorar, lo civil forma parte integral de lo económico. Ojalá que las peleas partidistas de los tres primeros meses de 1991 no marchiten estos brotes de concertación nacional, ni las últimas ofensivas de ambos contendientes armados saquen de la agenda a negociar los puntos de la impunidad, desmilitarización, derechos humanos y otras negras pinceladas que manchan la imagen nacional.

Si se perciben sensiblemente estos avances civiles y sociales, seria muy oportuno que los progenitores de nuestro modelo neoliberal hicieran una revisión de los principios filosóficos que introducen el Plan de Desarrollo, y los depuraran del individualismo y egocentrismo que resuman. Esos ideales son ciertos (libertad, igualdad, justicia, propiedad, competencia...) pero no al simple nivel individual de darwinismo social o supervivencia del más fuerte, sino a nivel integral de los más y de todos. A modo de reflexión ética hemos presentado algunas consideraciones al respecto bajo el título de "la democracia en los principios y postulados del modelo"15 No se trata de recomendar ningún estatismo o colectivismo, sino de imos compenentrando de estos ideales de solidaridad y democracia. Ojalá que en 1991 podamos editar una nueva tarjeta de felicitación:" Feliz Siglo-XXI".

15. Ibisate Foo. Javier: "El programa de ajuste estructural: una herencia dificil". Realidad Económico-Social. № 15. Mayo-junio, 1990. pp. 234, 239. 